\title{
Research on University Computer Teaching Model Based on MOOC+SPOC
}

\author{
Dongmei Fan*
}

\author{
Shandong Xiehe University, Yaoqiang Town, Licheng District, Jinan City China \\ *Corresponding author. Email: fandongmei5238@163.com
}

\begin{abstract}
With the further development of information technology, the traditional teaching model which is mainly characterized by face-to-face teaching in class, has brought out new demands in terms of new teaching technology, new teaching thinking and teaching result. "MOOC + SPOC" is a new mode which integrated online and offline learning, the traditional classroom, organic combination of network class and interaction class, promote student-centered teaching and learning, and effectively reflect the teacher to student learning and the guidance of thinking, increasing the interaction between students and teachers, improving students' autonomous learning ability and learning initiative[1].
\end{abstract}

Keywords: $M O O C, S P O C$, university computer, model of teaching

\section{INTRODUCTION}

Now in the society of information, information technology represented by computer and network has become a basic skill that contemporary college students must get .MOOC+SPOC is a hybrid teaching method, which is the reform direction of university computer teaching course. SPOC is a small-scale, restricted online classroom that emphasizes the combination of traditional and online teaching to implement online teaching for students [2]. The education of University if implement "employment as the guide, ability as the standard", it is necessary to comprehensive reform of the curriculum, and based on the MOOC + SPOC innovation model of computer teaching, it helps teachers finish college computer course better, promote the healthy and stable development, so as to improve the quality of basic computer teaching and teachers teaching level [3].

\section{CHALLENGES FACED BY UNIVERSITY TRADITIONAL COMPUTER TEACHING MODE}

The section headings are in boldface capital and lowercase letters. Second level headings are typed as part of the succeeding paragraph (like the subsection heading of this paragraph). Under the traditional teaching mode, the course objective of "university computer" is limited to the course knowledge system itself, and there is no public connection between the course objective and the subject and the professional course module[4]. The course orientation only focused on the general part, and the personalized demand related to the professional learning is not reflected or very weak. The objective of course is one size fits all equipotential line type, a principle of dividing course content in the traditional teaching environment is too single flat, not the embodiment of the more comprehensive information to new technology, new applications, reflect and combined with the new environment in the course, which could not reflect three-dimensional multi-level course content in the era of information technology in the environment demand, causing students optional learning is restricted.

The knowledge system of "university computer" has the characters of updated quickly, practical, innovative and more applicable. The traditional teaching mode which has limits and could not meet demand of students' fragmented time learning, multi-information channel and private space learning, which results in that it cannot fully mobilize the learning enthusiasm. This course is a course combining theory with practice. Combined with virtual experiment and online learning in the information technology environment, new element comes out, it makes the existing teaching evaluation system could not better reflect the characters just like practical and applied of this course, thus affecting the teaching evaluation results of the course.

Based on the above situation, we adopt the teaching model of MOOC+SPOC to provide college students with different online learning resources, so that college students can use the Internet for independent learning. At the same time, we can also interact with students in their spare time through the Internet to provide them with more learning time. MOOC could via the Internet to overcome geographical disadvantage, the students can watch high quality video lecture, exercise, BBS interaction, test, examination, on the Internet after registration. so that the students can be anywhere at any time, set the pace, self-regulation of learning, the students in the complicated problems encountered in the learning process, can be solved through class flip. 


\section{3. $\mathrm{MOOC}+$ SPOC}

\subsection{MOOC+SPOC can Promote Teaching}

The MOOC+SPOC platform is rich in teaching resources, which including courseware, teaching videos, course guidance documents, question Banks, e-books, and test questions[5].Through this platform, students can make use of the gathered resources effectively and learn more knowledge. In addition, this platform can make it true about automatic data collection, automatic performance processing and automatic assessment, providing a variety of support for teaching work.

Through the MOOC+SPOC platform, data can be gathered automatically with the deepening of teaching, which also saves the manual work time of teachers or other staff.

\subsection{Differentiation and Specialization Teaching}

Students' level and foundation are different and the applied teaching methods and teaching requirements are also different to the same course. For example, some students who are good at basic knowledge can learn more in limited time by only telling them once. But to the student with weak foundation, we must say repeatedly, and compress the content in effective time, such lets the student get easily . we should combine SPOC and MOOC because of the similarities and differences .MOOC can be builded with benchmark, and we can build characteristic SPOC course content on the basis of MOOC[6]. We can guarantee the teaching effect with the help MOOC, and students can receive high-quality teaching under different teachers, so as to achieve educational equity. SPOC make us achieve distinctive and differentiated teaching, so we can mobolize teachers and students' initiative and enthusiasm fully.

\subsection{Flipped Classroom}

Flipped classroom turns the traditional classroom into a network course, and the realization of flipped classroom requires certain conditions[7]. First, we should make sure students have completed the required learning tasks through MOOC+SPOC. Secondly, it should be small class teaching and discussion. We can adopt the teaching mode of "network first, classroom second" or "network second, classroom first". The specific implementation is as the following: First of all, the perfect teaching content will be placed in the network classroom, so that students can independently choose the learning content; But in the offline classroom it should be fine and few content to choose, and take consideration of the majority students. Secondly, network class is suitable for learning fragmented knowledge, so it is necessary to simplify the content of explanation ideas and key and difficult contents. In the offline class, we should pay attention to explaining these contents and guide students to learn more online classroom knowledge through communication and interaction. Thirdly, the online classroom is suitable for learning and self-learning without the limitation of space and time; In the offline class, students should show, communicate, discuss and comment on the results, which is conducive to independent learning. At present, the teaching model of MOOC+SPOC is under well being promoted in an increasingly wide range.

\subsection{The Third Class}

We call the traditional classroom the first class and call the online class the second class, we define the massive online discussion as the third class. We can effectively improve the teaching effect through making full use of the third class, Research shows that online discussions provide a wider range of ideas for students who are willing or unwilling to speak. Especially for those students who do not want to speak in class and increase their participation. Lots of students think the participation can make their opinion change, also promote their learning, and in this way they can find the gap between themselves and others, thus grasping their learning, so it can be said that the third class can play a very important role.

\section{UNIVERSITY COMPUTER TEACHING MODE REFORM BASED ON MOOC+SPOC}

\subsection{Build the Course Resource Platform and Standardize the Teaching Content}

To facilitate the combination of online and offline teaching, with the reference of domestic "east-west university Shared course alliance", "local colleges and universities" excellent class "alliance", "China computer education in colleges and universities MOOC union" and other MOOC teaching platform, love course syllabus, the accumulation of their own class "micro" video, testing database, comprehensive teaching resources construction. With the aid of MOOC, we can realize the co-construction and sharing of all students, and with the aid of SPOC we can realize the co-construction and sharing of various classes[8].

\subsection{Strengthen the Teaching Design to Meet the Multi-Level Learning Needs of Students}

Combining the teaching objectives, characteristics of learners, teaching environment and teaching resources of university computer course, a new model of "role reversal" 
is proposed on the basis of flipped classroom. The specific operation process is shown in figure 1 below.

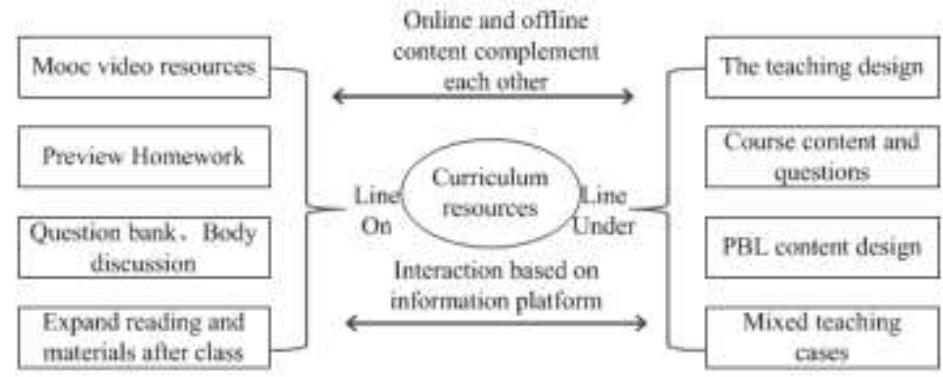

Figure 1 "MOOC+ flip" teaching model

In the past flipped classroom, students usually communicate and discuss in class after independently learning the teaching video and sorting out the content and problems by themselves. Using guided learning case, we can build hierarchical inquiry activity, students could do small problems inquiry in small group after the video learning. First they can take part in the personal Q\&A exchange meeting, internalize the knowledge and summarize it into the guidance case[9]. Teachers will guide students to solve the key and difficult problems in class and answer the questions for the second time. Which will enlarge the Q\&A arrange and improve the quality of the classroom problem inquiry activity.

\subsection{The Establishment of Teaching Mode, Guide Students Independent Learning}

Based on previous reach on "MOOC + Flip" diversified teaching mode, we improve the optimization the preliminary build "MOOC + SPOC" teaching model and we finally build the teaching mode as shown in figure. 2 to continue the practical exploration.

Students listen to the teacher in class and after class they will primarily base on love course platform associated source "University Computer" to autonomous learning. According to their own learning objectives, make full use of online learning resources for learning. According to their learn objective, the students will take well use of the online learning resourcing to strengthen knowledge points. We build our own SPOC in love course platform. in using MOOC resources at the same time, the teacher added to the coursewareaccording to the actual needs of students. After class, students use the exclusive discussion area of SPOC to discuss and communicate within the class, answer questions with each other, share their learning experience and get growth together. After get family with teaching platform preliminary, we organizes the student to communicate, share the learning, we put forward the "MOOC + SPOC" teaching mode, we think that this teaching mode improve the learning efficiency.

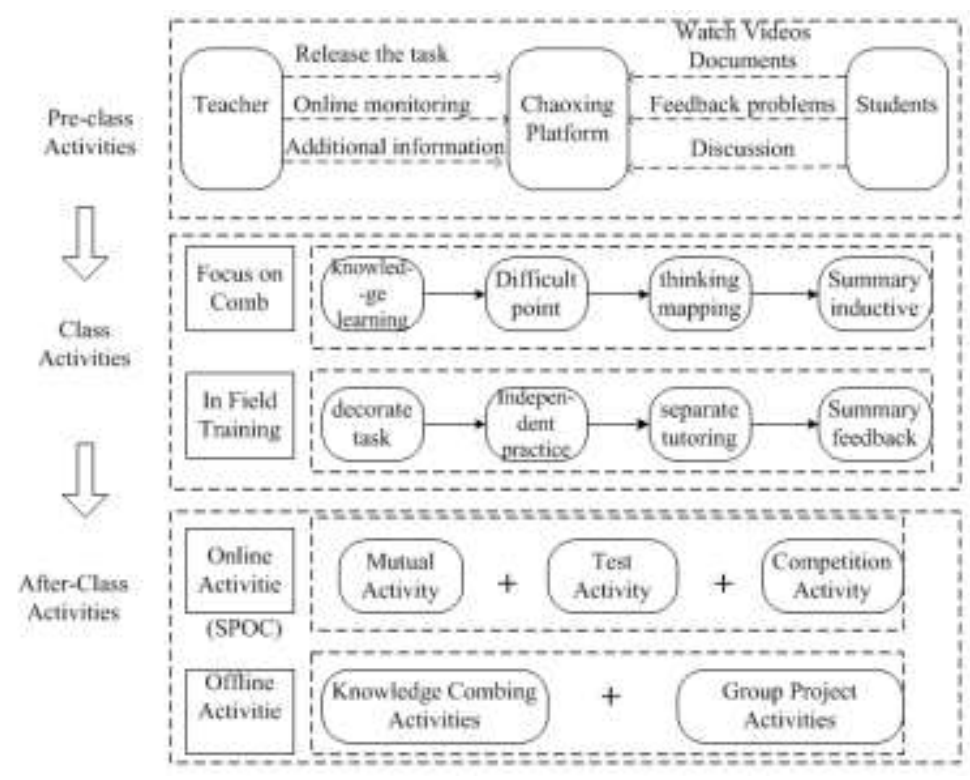

Figure 2 "MOOC+SPOC" teaching model 


\subsection{The Practice of the Teaching Mode and Guide Students to Learning Effectively}

Teaching practice is carried out for students majoring in computer and other majors in the course of university computer, In the process of teaching practice, to assist teachers to teach through the management of students' online learning, offline planning activities, design online learning activities, etc[10]. We Collect and analyze the actual problems and adjust the teaching activities timely and combined with the teaching activity design, in the course of teaching practice, we use the questionnaire survey and the SPSS questionnaire analysis, understand the students basic situation before the class, learning objectives, after-class learning situation and emotional attitude, and the use of classroom observation method, to understand the students' learning status, analysis of students online learning data, combined with the learning effect and the actual teaching situation, to further optimize the constructed teaching model

\subsection{Build a Teaching Evaluation System, Improve the Quality of Teaching}

To combine of process evaluation and test evaluation. it comprehensively reflects the unity and effective combination of process learning and outcome learning in teaching evaluation. Among this, the evaluation for course process mainly depends on the online learning platform support, collect the fragmentation of the students learning time and online discussion; the evaluation for test is mainly to enrich test evaluation methods and factors, such as online and offline questions and answers, online and offline quizzes, online and offline job evaluation and exhibition. The evaluation method combined with process evaluation and test evaluation can better reflect the evaluation of course learning, not just the evaluation of learning results. Because the online evaluation reflects the evaluation of learners' learning ability, combined with the offline evaluation of results, the teaching can be evaluated more comprehensively and effectively, comprehensively reflecting the unity of teaching ability and teaching results.

\section{SUMMARY}

In the "Internet $+"$ environment, as a new teaching mode relying on the Internet and mobile Internet, MOOC has caused a new wave of teaching reform. In order to improve the quality of talent development, colleges and universities need to re-examine and adjust the orientation of talent development objectives in the process of professional certification, which inevitably puts forward new requirements on the teaching mode [11]. On the basis of
MOOC+SPOC, the reform of university computer course teaching could not only enrich the teaching content and form, but also realize the co-construction and sharing, improve students' learning ability effectively, so that they can learn more knowledge, and the way of reform needs us to continue to explore.

\section{REFERENCES}

[1] Zhang Chun-Ying, Liu Ying, Zhao Yan-Jun. Research on Flipped Classroom Teaching Model of "University Computer Foundation" Based on "MOOC+SPOC"[J]. Network and Digitization.2016 (3).

[2] Xun Wei, Jia Yong-Zheng. From MOOC to SPOC -An Academic Dialogue Based on the MOOC Practice at UC Berkeley and Tsinghua University[J]. Modern Distance Education Research.2014(4).

[3] Wang Rui. A Practical study on the Teaching Model of "MOOC+SPOC+ flipped classroom"[D].Chongqing: Chongqing Normal University,2019.

[4] Ma Fu-Xiang. Research on the Teaching ModeL of "University Computer Foundation" course based on MOOC+SPOC $[\mathrm{J}]$. Production, Theory and Practice,2019,27(17).

[5] Tang Jun-Lin. Based on the MOOC + SPOCs University Computer Teaching reform Practice research $[\mathrm{J}]$. Electronic Components and Information Technology ,2018,2(9).

[6] Nie Qing, Lu Can-Ju, Zhang Yun-Feng. Based on the $\mathrm{MOOC}+$ SPOCs Research University Computer Foundation course Teaching Reform [J]. Education Technology,2018,17(2).

[7] Liu Yun-Fang, Zuo Wei-Ping, Li Hai-Yun. Based on MOOC + SPOC Practice Teaching of University Computer Course[J]. Education ,2019,2(2).

[8] Chi Ya-Qing, Song Rui-Qiang, Li Zhen-Tao. Explore the Impact of MOOC on the Teaching of Computer Courses. Computer Engineering and Science, 2014,36(s1)

[9] Zhang Ying-Chun. Discussion on the Teaching Assessment Method of Computer Course[J]. Journal of Southwest Normal University (Natural Science Edition), 2012,37(7).

[10] Li Ling-Xia, Wang Xiao, Xie Yong-hong. Compound Teaching Reform Pratice of"MOOC+SPOC+Flip Classroom"-Taking 
"Introduction to Computer" Course as an Example

[J].Heilongjiang Education(Theory and

Practice),2018(09).

[11] Zhan De-chen.Implementation Plan of Compound

Teaching Reform of "University

Computer","MOOC+SPOCs+Flip Classroom"

[J].Computer Education,2016(01). 